\title{
Growth, Water Relations and Ion Accumulation in Phlomis Purpurea Plants under Water Deficit and Salinity
}

\author{
S. Álvarez ${ }^{1}$, M.J. Gómez-Bellot ${ }^{1}, \mathrm{~S}$. Bañón ${ }^{2,3}$ \\ ${ }^{1}$ Departamento de Riego, CEBAS-CSIC \\ P.O. Box 164. 30100. Murcia, Spain \\ ${ }^{2}$ Departamento de Producción Vegetal \\ Universidad Politécnica de Cartagena \\ 30203 Cartagena. Murcia, Spain
}

\author{
M.J. Sánchez-Blanco ${ }^{1,3}$ \\ ${ }^{3}$ Unidad Asociada al CSIC \\ Horticultura Sostenible en Zonas \\ Áridas \\ 30203 Cartagena. Murcia, Spain
}

Keywords: water stress; salinity; water potential; osmotic adjustment; Mediterranean shrub

\begin{abstract}
The effect of different levels of water deficit and salinity on physiological and morphological alterations in Phlomis purpurea plants was studied to evaluate their adaptability to such conditions. $P$. purpurea plants growing under greenhouse conditions were subjected to four irrigation treatments between November and May

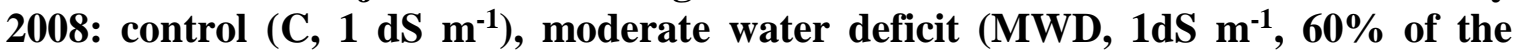
control), severe water deficit (SWD, $1 \mathrm{dS} \mathrm{m}^{-1}, 40 \%$ of the control) and saline (S, 4dS $\mathrm{m}^{-1}$ ). Aerial dry weight decreased with salinity, response that was more marked in the water deficit treatments, especially SWD. Stem diameter and leaf number were similarly reduced in both water deficit treatments, while leaf area also decreased in saline treated plants. Throughout the experiment, plant height was similar in both control and saline treated plants and was inhibited 10 weeks after application of the deficit irrigation onwards. Only at the end of the experiment were there significant differences in plant height between all treatments. Plants irrigated with saline water had higher $\mathrm{Na}^{+}$concentrations in their leaves than in their roots and shoots, while $\mathrm{Cl}^{-}$concentrations were similar in leaves and roots, suggesting some resistance to the movement of the latter ions from root to shoots. The accumulation of salt in the leaves was associated with osmotic adjustment, which maintained midday leaf turgor in saline treated plants. However, no osmotic adjustment was observed in plants submitted to water stress. The results indicate that the effect of osmotic stress due to water deficit was more severe than the toxic effect of salt.
\end{abstract}

\section{INTRODUCTION}

Many studies have confirmed the ability of Mediterranean woody plants to adjust their morphology and physiology to stressful environmental conditions (Mugnai et al., 2005). However, depending on the species and the source of the stress, plants respond in different ways (Azza Mazher et al., 2007). Salinity and drought are the major constraints affecting physiological processes, whose effects may have severe consequences for plant growth and survival in semiarid regions (Vilagrosa et al., 2003). The use of salt and drought- tolerant species for revegetation or xerogarden projects is a good practice since such plants maintain a normal appearance, despite water and saline stresses. Although early responses to water and salt stress are very similar, some halophytes can tolerate salt stress, but not drought and some xerophytes can tolerate drought, but not salt stress. Drought and saline tolerance in plants may be explained by the involvement of functional 
and structural adaptations, such as growth regulation, osmotic adjustment, and changes in water potential (Zollinger et al., 2007; Sánchez-Blanco et al., 2002), mineral nutrition changes, and hormone balance, all of which can alleviate the harmful effects of both stresses (Azza Mazher et al., 2007). These mechanisms may allow plants to survive during drought and in saline conditions but they do not mean that the plants will have high visual quality. Even plants that have some degree of drought and/or salinity tolerance may show reductions in quality when exposed to stress (Cameron et al., 1999).

Phlomis purpurea is a Mediterranean shrub of great interest for ornamental use. However, little is known about its physiological responses to different degrees of drought and water salinity. The purpose of this work was to study the effects on P. purpurea plants of the most important abiotic stresses (salinity and drought) which may occur during the nursery phase or in landscaping. Growth, water relations and $\mathrm{Na}^{+}$and $\mathrm{Cl}^{-}$ uptake and partitioning between organs were evaluated to know whether the changes observed in the plants exposed to drought and salinity may confer stress-resistance to the plant. Knowledge of the salt and drought response of ornamental plants may help the horticultural sector (growers and gardeners) to select species which are more tolerant to salt and water stress, and whose general appearance in such conditions is maintained.

\section{MATERIALS AND METHODS}

Rooted cuttings of Phlomis purpurea (Purple Phlomis) grown in 5x5x11 cm pots by a specialized nursery were transplanted into $4 \mathrm{~L}$ plastic pots $(15 \times 15 \times 20 \mathrm{~cm})$ filled with a $5: 4: 1(\mathrm{v} / \mathrm{v} / \mathrm{v})$ mixture of black peat: coconut fibre: perlite, amended with $2 \mathrm{~g} \mathrm{~L}^{-1}$ of Osmocote Plus (14:13:13 N,P,K plus microelements). Plants were placed inside a plastic greenhouse equipped with a cooling system, located at Santomera (Murcia, Spain).

After five weeks in the greenhouse, the plants were subjected to four irrigation treatments (42 plants per treatment) using a computer-controlled drip irrigation system from November 2007 to May 2008. The irrigation treatments consisted of $100 \%$ water holding capacity [(leaching $15 \%(\mathrm{v} / \mathrm{v})$ of the applied water, $1 \mathrm{dS} \mathrm{m}^{-1}$; Control )], $60 \%$ of the control irrigation water, $1 \mathrm{dS} \mathrm{m}^{-1}$ (moderate water deficit; MWD), $40 \%$ of the control irrigation water, $1 \mathrm{dS} \mathrm{m} \mathrm{m}^{-1}$ (severe water deficit; SWD) and a saline treatment using tap water with salt added up to $44 \mathrm{mM} \mathrm{NaCl}\left(4 \mathrm{dS} \mathrm{m}{ }^{-1} \mathrm{~S}\right)$. One drip nozzle delivering $2 \mathrm{~L} \mathrm{~h}^{-1}$ per pot was connected to two spaghetti tubes (one each side of every pot) and the duration of each irrigation episode in the control plants was used to vary the amount of water applied, which depended on the season and on climatic conditions. For the saline treatment, the irrigation water was applied in such a way as to maintain the electrical conductivity of the drainage water at about $\pm 10 \% \mathrm{EC}$ of the irrigation water supplied for this treatment. The volume of water varied between 200 and $500 \mathrm{ml}$ per pot and irrigation episode for the controls.

At the end of the experimental period, the substrate was gently washed from the roots of eight plants per treatment and the plants were divided into shoots (i.e., leaves and stems) and roots. These were then oven-dried at $80{ }^{\circ} \mathrm{C}$ until they reached a constant weight to measure the respective dry weights (DW). Stem diameter $(\mathrm{mm})$, leaf number and leaf area $\left(\mathrm{cm}^{2}\right)$, using a leaf area meter (Delta-T; Devices Ltd., Cambridge, UK), were determined in the same plants. Through the experiment, plant height was measured in 20 plants per treatment.

At the end of the experimental period, eight plants per treatment were harvested and separated into leaves, stems and roots. These were washed with distilled water, dried at $70{ }^{\circ} \mathrm{C}$ and stored at room temperature for inorganic solute analyses. The concentration 
of $\mathrm{Cl}^{-}$was analysed in the aqueous extracts by a chloride analyzer (Chloride analyzer mod. 926, Sherwood Scientific Ltd.). The concentrations of $\mathrm{Na}^{+}$were determined in a digestion extract with $\mathrm{HNO}_{3}: \mathrm{HClO}_{4}(2: 1, \mathrm{v} / \mathrm{v})$ by an ICP-OES IRIS INTREPID II XDL analyzer.

Seasonal changes in leaf water potential $\left(\Psi_{1}\right)$ at midday and leaf osmotic potential at full turgor $\left(\Psi_{100 s}\right)$ were measured in five plants per treatment. $\Psi_{1}$ was estimated according to Scholander et al. (1965), using a pressure chamber (Model 3000; Soil Moisture Equipment Co., Santa Barbara, CA, USA) in which leaves were placed in the chamber within $20 \mathrm{~s}$ of collection and pressurised at a rate of $0.02 \mathrm{MPa} \mathrm{s}^{-1}$ (Turner, 1988). Leaf osmotic potential at full turgor $\left(\Psi_{100 \mathrm{~s}}\right)$ was estimated according to Gucci et al. (1991), using excised leaves with their petioles placed in distilled water overnight to reach full saturation. Leaves from the $\Psi_{100 \text { s }}$ measurements were frozen in liquid nitrogen $\left(-196{ }^{\circ} \mathrm{C}\right)$ and stored at $-30{ }^{\circ} \mathrm{C}$. After thawing, the osmotic potential was measured in the extracted sap using a WESCOR 5520 vapour pressure osmometer (Wescor Inc., Logan, UT, USA).

The experiment consisted of a randomized block design, where a single block referred to a single treatment. The data were analysed by one-way ANOVA using Statgraphics Plus for Windows 5.1 software. Ratio and percentage data were subjected to an arcsine square-root transformation before statistical analysis to ensure homogeneity of variance. Treatment means were separated with Duncan's Multiple Range Test $(\mathrm{P} \leq 0.05)$.

\section{RESULTS}

Salinity and drought stress affected the growth and size of phlomis plants, with a significant decrease in aerial and root DW and leaf area being measured at the end of the experiment (Table 1). However, the exact effect depended on the treatments and parameters. Drought had a more marked effect, especially SWD on aerial DW. Stem diameter and leaf number were similarly reduced in both water deficit treatments, in addition leaf area was decreased also in saline plants (Table 1). As regards biomass distribution in different parts of the plants with respect to total biomass production, no differences between the control and saline treatment were observed, and higher root /shoot ratios were found in the SWD treatment (Table 1). Throughout the experiment, plant height was similar in both the control and saline treatments, but was inhibited 10 weeks after application of the deficit irrigation onwards (Fig. 1). Only at the end of the experiment there were significant differences in plant height in all treatments, the smallest plants $(38 \mathrm{~cm})$ being those subjected to severe water stress.

Salinity had a pronounced effect on $\mathrm{Cl}^{-}$and $\mathrm{Na}^{+}$concentrations, while no accumulations of these ions were observed in the plants subjected to water stress (Fig. 2). The concentrations of both ions increased with salinity in different parts of the plants (root and leaf). In general less $\mathrm{Na}^{+}$was accumulated than $\mathrm{Cl}^{-}$. At the end of the experiment in the saline treatment, $\mathrm{Na}^{+} / \mathrm{Cl}^{-}$ratios were 0.94 for leaves, 0.68 for stems and 0.45 for roots. The distribution of both ions in the different part of the plants was different. Plants irrigated with saline water had higher $\mathrm{Na}^{+}$concentrations in their leaves than in their roots and shoots, while $\mathrm{Cl}^{-}$concentrations were similar in leaves and roots.

As regards leaf water potential $\left(\Psi_{1}\right)$, a decrease of its values was observed in the stress treatments, especially in SWD (Fig. 3). At the end of the experimental period, in SWD treatment $\Psi_{1}$ reached values of around -3.0 MPa. No differences in $\Psi_{100 \text { s }}$ between the water stress treatments and the control were found during the experimental period 
(data not shown), pointing to an absence of osmotic adjustment in these treatments. While

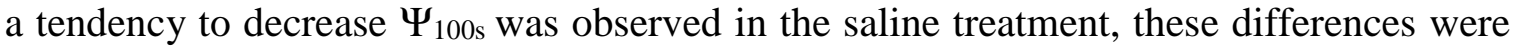
significant at the end of the experimental period (-1.3 and -1.6 MPa for $\mathrm{C}$ and $\mathrm{S}$, respectively)

\section{DISCUSSION}

Ornamental shrubs in general have demonstrated wide variability in their reaction to water stress and salinity. The responses of plant species to salinity and osmotic stress in terms of growth are the ultimate expression of several interacting physiological and biochemical parameters (Sidari et al., 2008). In our conditions, both soil drying and salinity reduced plant growth, especially in drought plants, which showed the lowest values of dry weight in both stems and leaves, resulting in an increased root/shoot dry weight ratio (Maggio et al., 2005). This latter response was not maintained when plants were subjected to salinity. The different distribution of biomass induced by both stress situations may be due to the need to maintain a higher root surface area under drought conditions and to reduce root volume in plants exposed to salinity, which may be a favourable trait limiting their capacity to accumulate toxic ions in the shoot (Munns, 2002; Alarcón et al., 2006).

The effect of salt stress and water stress on plant growth and dry matter accumulation has been described in several crops species (Rodríguez et al., 2005; Sánchez-Blanco et al., 2002). Reductions in leaf canopy surface have been considered to be an avoidance mechanism which minimises water loss under stress conditions (Savé et al., 1994). As regards saline treatment, it is well known that salinity reduces vegetative and reproductive growth of non-halophytes (Azza Mazher et al., 2007). Ornamental plants and woody trees vary in their degree of salinity tolerance from sensitive to very tolerant. Phlomis could be considered relatively salt tolerant species as it showed little growth reduction and few symptoms of leaf injury, both factors that have been used as a measure of resistance to saline conditions (Sánchez-Blanco et al., 1991).

As plant water status is concerned, the leaf water potential values observed indicate that severe water stress caused a strong dehydration throughout the experiment at midday due to difficulty in taking-up water from the substrate (osmotic effect), which have often been considered to be responsible for growth inhibition.

The observed decrease in leaf osmotic potential at full turgor in salinized plants points to the osmotic adjustment process that takes place under these conditions. Such osmotic adjustment permitted the turgor potential to be maintained in treated saline plants throughout the experiment in spite of the moderate osmotic adjustment developed $(0.2$ $\mathrm{MPa}$ ). This behaviour and the values of osmotic adjustment reported in this work are within those reported for other studies on Mediterranean ornamental plants submitted to saline stress (Navarro et al., 2008; Sánchez-Blanco et al., 1998).

$P$. purpurea may behave as a typical $\mathrm{Na}^{+}$includer, compartmentalizing $\mathrm{Na}^{+}$and $\mathrm{Cl}^{-}$within the leaf cell vacuoles where it could be used as osmoticum to lower the osmotic potential necessary for the maintenance of leaf turgor. Osmotic adjustment was not observed in plants subjected to drought. This could indicate that these solutes were responsible for the osmotic adjustment described above. In relation to the comparative physiology of osmotic adjustment in saline versus dry soil there is the issue of metabolic costs. The cost of intracellular compartmentation is relatively small in relation to that needed to synthesize organic solutes for osmotic adjustment (Munns, 2002). 
In conclusion, our results indicate that although reduced irrigation and the use of saline water could be useful for controlling plant size in Phlomis purpurea as a flowering pot plant, the morphological and physiological responses differ significantly between salinity and water stress. Severe stress induced an excessive decrease in plant height and growth due to leaf tissue dehydration. In moderate water stress, all these responses were mitigated. Salt may improve the response of $P$. purpurea to water stress as a result of slight growth reduction and the lack of toxicity symptoms related to osmotic adjustment. It can be inferred that the use of saline water (around $4 \mathrm{dS} \mathrm{m}^{-1}$ ) is feasible for growing this ornamental plant commercially, a consideration that is particularly relevant in arid saline areas.

\section{ACKNOWLEDGEMENTS}

This work was supported by the projects: CICYT (AGL 2008-05258-C02-1-2), CDTI (IDI-20070868) and Convenio de la Consejería de Agricultura y Agua de la Región de Murcia-UPCT-CEBAS, 2008.

\section{Literature Cited}

Alarcón, J.J., Morales, M.A., Ferrández, T. and Sánchez-Blanco, M.J. 2006. Effects of water and salt stresses on growth, water relations and gas exchange in Rosmarinus officinalis. J. Hort. Sci. Biotehcnol. 81: 845-853.

Azza Mazher, A.M., Fatma El-Quesni, E.M. and Farahat, M.M. 2007. Responses of ornamental plants and woody trees to salinity. World J. Agric. Sci. 3: 386-395.

Cameron, R.W.F., Harrison-Murray, R.S. and Scott, M.A. 1999. The use of controlled water stress to manipulate growth of container-grown Rhododendron cv. Hoppy. J. Hort. Sci. Biotechnol. 74:161-169.

Gucci, R., Xiloyannis, C. and Flore, J.A. 1991. Gas exchange parameters water relations and carbohydrate partitioning in leaves of field-grown Prunus domestica following fruit removal. Physiol. Plant. 83: 497-505.

Maggio, A., De Pascale, S., Ruggiero, C. and Barbieri, G. 2005. Physiological response of field-grown cabbage to salinity and drought stress. Eur. J. Agron. 23: 57-67.

Mugnai, S., Vernieri, P., Malorgio, F. and Serra, G. 2005. Response of some ornamental shrubs to different soil water conditions. Adv. Hort. Sci. 19: 94-100.

Munns, R. 2002. Comparative physiology of salt and water stress. Plant Cell Environ. 25: 239-250.

Navarro, A., Bañón, S., Conejero, W. and Sánchez-Blanco, M.J. 2008. Ornamental characters, ion accumulation and water status in Arbutus unedo seedlings irrigated with saline water and subsequent relief and transplanting. Environ. Exp. Bot. 62: 364370

Rodríguez, P., Torrecillas, A., Morales, M.A., Ortuño, M.F. and Sánchez-Blanco, M.J. 2005. Effects of $\mathrm{NaCl}$ salinity and water stress on growth and leaf water relations of Asteriscus maritimus plants. Environ. Exp. Bot. 53: 113-123

Sánchez-Blanco, M.J., Bolarín, M.C., Morales, M.A., Alarcón, J.J. and Torrecillas, A. 1991. Salinity effect on water relations in Lycopersicum esculentum and its wild salttolerance relative species, L. pennellii. Physiol. Plant. 83: 269-274.

Sánchez-Blanco, M.J., Morales, M.A., Torrecillas, A. and Alarcón, J.J. 1998. Diurnal and seasonal osmotic potencial changes in Lotus creticus plants grown under saline stress. Plant Sci. 136: 1-10. 
Sánchez-Blanco, M.J., Rodríguez, P., Morales, M. A., Ortuño, M. F. and Torrecillas, A. 2002. Comparative growth and water relation of Cistus albidus and Cistus monspeliensis plants during water deficit conditions and recovery. Plant Sci. 162: 107113

Savé, R., Olivella, C., Biel, C., Adillón, J. and Rabella, R. 1994. Seasonal patterns of water relationships, photosynthetic pigments and morphology of Actinidia deliciosa plants of the Haywards and Tomouri cultivars. Agronomie 2: 121-126

Scholander, P.F., Hammel, H.T., Bradstreet, E.D. and Hemingsen, E.A. 1965. Sap pressure in vascular plants. Scientia 148: 339-346.

Sidari, M., Mallamaci, C. and Muscolo, M. 2008. Drought, salinity and heat differently affect seed germination of Pinus pinea. J. Forest Res. 13: 326-330.

Turner, N.C. 1988. Measurement of plant water status by the pressure chamber technique. Irrig. Sci. 9: 289-308.

Vilagrosa, A., Bellot, J., Vallejo, V.R. and Gil-Pelegrín, E. 2003. Cavitation, stomatal conductance, and leaf dieback in seedlings of two co-ocurring Mediterranean shrubs during an intense drought. J. Exp. Bot. 54: 2015-2024.

Zollinger, N., Koenig, R., Cerny-Koenig, T. and Kjelgren, R. 2007. Relative salinity tolerance of Intermountain Western United States native herbaceous perennials. HortScience 42: 529-534.

\section{Tables}

Table 1. Growth and ornamental parameters at the end of the experiment in $P$. purpurea plants subjected to water deficit and salinity.

\begin{tabular}{|c|c|c|c|c|c|c|c|}
\hline \multirow{2}{*}{ Parameters } & \multicolumn{6}{|c|}{ Treatments } & \multirow[t]{2}{*}{$\mathrm{P}$} \\
\hline & $\mathrm{C}$ & & S & & MWD & SWD & \\
\hline Aerial DW (g plant ${ }^{-1}$ ) & 32.42 & $\mathrm{a}$ & 22.95 & $\mathrm{~b}$ & $16.34 \mathrm{c}$ & $11.09 \mathrm{~d}$ & $* * *$ \\
\hline Root DW (g plant ${ }^{-1}$ ) & 24.60 & $\mathrm{a}$ & 17.83 & $\mathrm{~b}$ & $16.63 \mathrm{~b}$ & $15.37 \mathrm{~b}$ & $* * *$ \\
\hline Total DW (g plant $\left.{ }^{-1}\right)$ & 57.02 & $\mathrm{a}$ & 40.77 & $\mathrm{~b}$ & $32.97 \mathrm{c}$ & $26.47 \mathrm{~d}$ & $* * *$ \\
\hline Leaf part $(\%)$ & 36.81 & $\mathrm{c}$ & 38.15 & $\mathrm{c}$ & $32.38 \mathrm{~b}$ & $28.09 \mathrm{a}$ & $* * *$ \\
\hline Stem part $(\%)$ & 20.23 & $\mathrm{~b}$ & 18.09 & $a b$ & $17.22 \mathrm{ab}$ & $13.84 \mathrm{a}$ & $*$ \\
\hline Root part $(\%)$ & 42.96 & $\mathrm{a}$ & 43.76 & $\mathrm{a}$ & $50.39 \mathrm{~b}$ & $58.08 \mathrm{c}$ & $* * *$ \\
\hline Total leaf area $\left(\mathrm{cm}^{2}\right)$ & 2084 & $\mathrm{a}$ & 1639 & $\mathrm{~b}$ & $851 \mathrm{c}$ & $658 \mathrm{c}$ & $* * *$ \\
\hline Stem diameter $(\mathrm{mm})$ & 6.31 & $\mathrm{a}$ & 5.95 & $\mathrm{a}$ & $4.56 \mathrm{~b}$ & $4.50 \mathrm{~b}$ & $* * *$ \\
\hline Leaf number & 160 & $\mathrm{a}$ & 146 & $\mathrm{a}$ & $109 \mathrm{~b}$ & $112 \mathrm{~b}$ & $* * *$ \\
\hline Root/Shoot ratio & 0.79 & $\mathrm{a}$ & 0.79 & $\mathrm{a}$ & $1.03 \mathrm{a}$ & $1.42 \mathrm{~b}$ & $* * *$ \\
\hline
\end{tabular}

Means within a row without a common letter are significantly different by Duncan 0.05 test. 


\section{Figures}

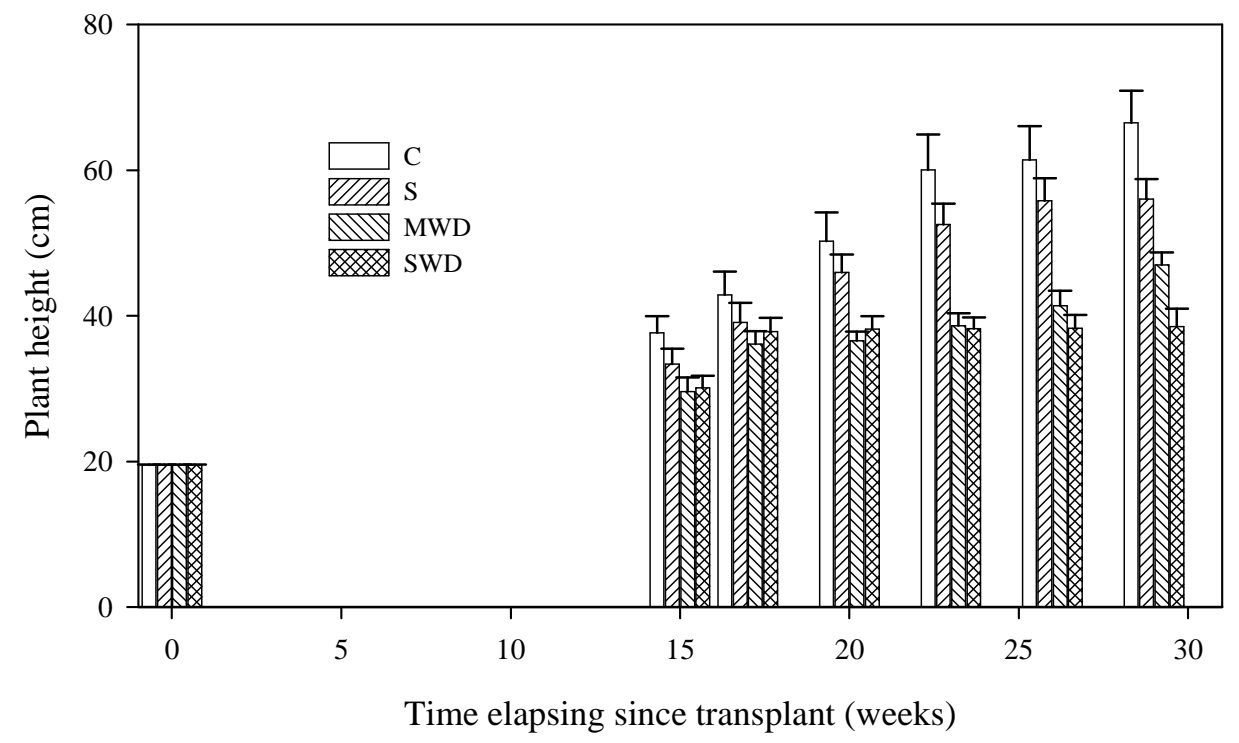

Fig. 1. Height of P. purpurea plants subjected to water deficit and salinity. Values are means of 20 plants per treatment and the vertical bars indicate standard errors.

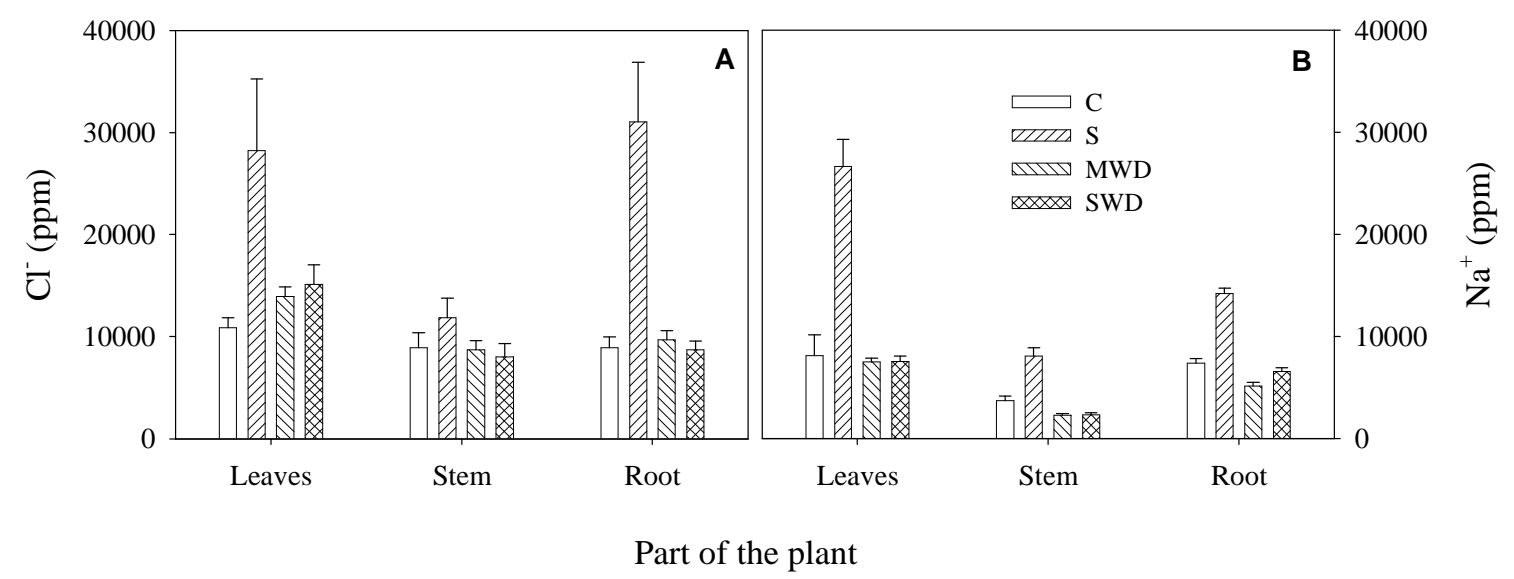

Fig. 2. $\mathrm{Cl}^{-}$and $\mathrm{Na}^{+}$concentrations at the end of the experiment in P. purpurea plants subjected to water deficit and salinity. Values are means of eight plants per treatments and the vertical bars indicate standard errors. 


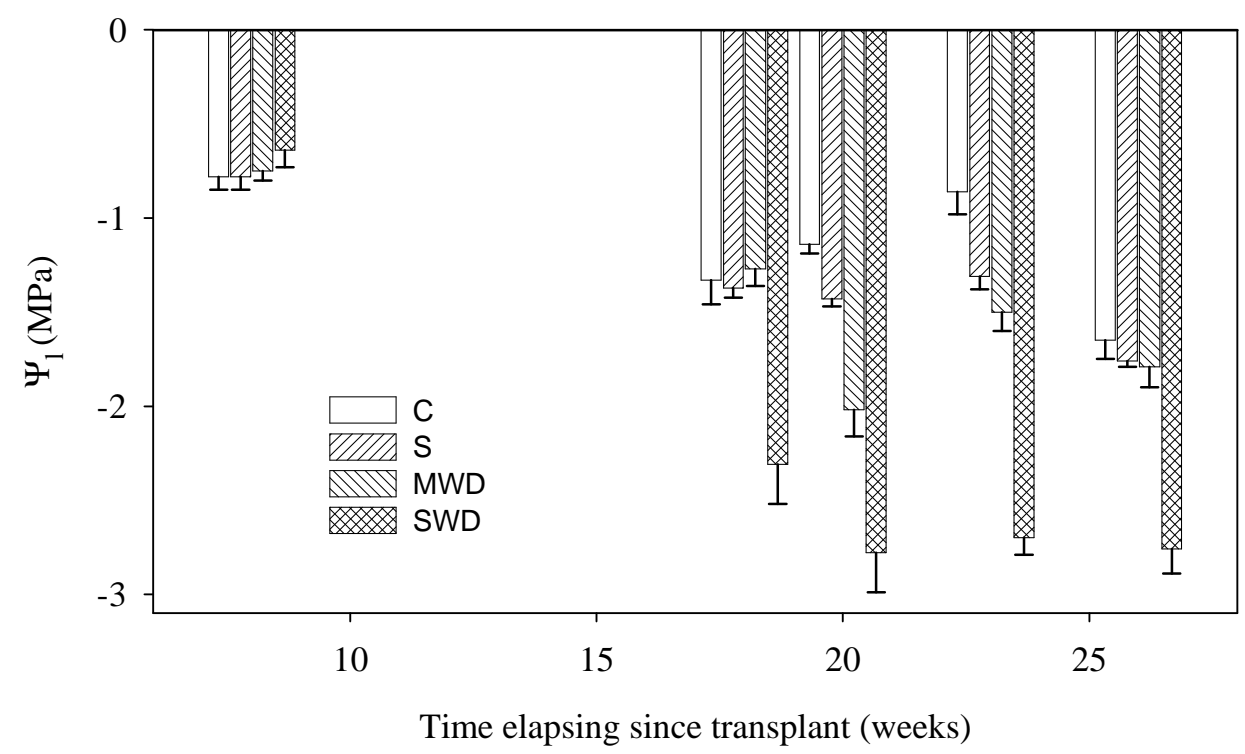

Fig. 3. Evolution of leaf water potential at midday $\left(\Psi_{1}\right)$ in $P$. purpurea plants subjected to water deficit and salinity. Values are means of five plants per treatments and the vertical bars indicate standard errors. 